\title{
O NATURALISMO PRESENTE NA VISÃO DE PROFESSORES SOBRE MEIO AMBIENTE E AS MARCAS DA EDUCAÇÃO AMBIENTAL CONSERVADORA
}

Magnus José Barros Gonzaga ${ }^{1}$

Resumo: Este artigo discute o naturalismo presente na concepção de meio ambiente de professores de escolas públicas. $O$ artigo é resultado de pesquisa desenvolvida em nível de mestrado, a qual objetivou identificar, conhecer e cartografar: a) as experiências pedagógicas em Educação Ambiental; b) a concepção de meio ambiente presente na prática pedagógica dos professores; e c) as matrizes teórico-metodológicas que fundamentam as experiências dos professores de escolas selecionadas da Rede Municipal de Ensino de Natal, $\mathrm{RN}$. A pesquisa desenvolvida constata que predomina a visão naturalista no tocante a concepção de meio ambiente dos professores.

Palavras-chave: Educação Ambiental; Perspectiva Crítica; Concepção de Meio Ambiente.

1 Universidade Federal do Rio Grande do Norte. E-mail: magnusgorky@gmail.com 


\section{Introdução}

A pesquisa científica no campo da Educação Ambiental pode situarse dentro de novas formas de ação social aptas a abrir caminhos ou perspectivas contra-hegemônicas do ponto de vista cognitivo, político, ético e social. Como salienta Ruscheinsky (2005, p.135) "a pesquisa em Educação Ambiental consiste em um inquérito sobre um fenômeno socioambiental ou exame cuidadoso para descobrir novas informações ou relações, possibilitando ampliar e verificar o conhecimento existente". Nesse sentido, considera-se que a pesquisa em Educação Ambiental vem ocupando, paulatinamente, seu espaço na produção científica, teórica e epistemológica em torno da área, processo que pode se constatar ao verificar o estudo de (CARVALHO, 2011).

Dessa forma, para descobrir novas informações e ampliar o nosso universo conceitual sobre o assunto, foi preciso adentrar no tecido da vida social da escola, e, assim, consolidar os objetivos do nosso trabalho, isto é, fazer pesquisa empírica. Para tanto, tivemos que nos aproximar e vivenciar pelo menos, em parte, o dia-a-dia da escola, sujeito-objeto de nossas inquietações.

O presente artigo é parte de uma pesquisa mais ampla, desenvolvida em nível de Mestrado, cuja pesquisa buscou identificar, analisar e cartografar as experiências pedagógicas em Educação Ambiental (EA) de escolas públicas - selecionadas aleatoriamente por sorteio - da Rede Municipal de Ensino de Natal (RN) (Quadro 1). Para fins desse artigo, discute-se a concepção de meio ambiente presente na prática pedagógica em Educação Ambiental (EA) desenvolvida por professores nessas escolas.

Quadro 1: Representação da amostra das escolas da Rede Municipal de Ensino de Natal (RN) por Regiões Administrativas da cidade de Natal (Não constam os Centros de Educação Infantil).

\begin{tabular}{|c|c|c|c|}
\hline Adiministrativas da? & 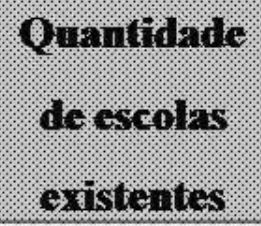 & 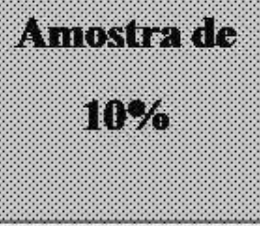 & Uscolas \\
\hline Norte & 31 & 3 Escolas & $\mathrm{A}, \mathrm{B}$ e C \\
\hline Sul & 9 & 1 Escolis. & G \\
\hline Leste & 9 & 1 Escolas & $\mathrm{E}$ \\
\hline Oeste. & 22. & 2) Irscolas & Der \\
\hline Total de escolas & 71 & 7 Escolas & \\
\hline
\end{tabular}


Para efeitos de nossa interpretação e análise sobre a concepção de meio ambiente dos professores, identificamos algumas categorias conceituais que integram a dimensão do meio ambiente, a partir da visão dos professores, as quais se configuram em: a) elementos físico-biológicos; b) relações de espacialidade e c) relações sociais. Na visão dos professores, os elementos físico-biológicos estão intrinsecamente relacionados às diversas formas de vida em toda a sua totalidade o que inclui também o homem, mas não necessariamente a intervenção que este desenvolve no meio por intermédio da cultura. As relações de espacialidade estão relacionadas aos espaços geográficos, ao lugar no qual se habita ou se vive; as relações sociais dizem respeito às intervenções humanas deixadas no meio ambiente pela sociedade, que nesse caso, estão representadas pelas questões políticas e sociais que promovem a dialética da dinâmica social.

$\mathrm{Na}$ transcrição das falas elencadas, tanto as escolas, como os professores e professoras receberam nomes próprios fictícios, a fim de preserva-se suas identidades.

Integraram a amostra, doze professores com a seguinte formação: geografia (2), química (1), que lecionava a disciplina de ciências, letras (1), formação em magistério nível médio ${ }^{2}$ (2), pedagogia (3), artes (2), biologia (1), totalizando doze professores. Os docentes, cuja formação era em magistério, nível médio, juntamente com os que possuíam formação em pedagogia ensinavam em turmas de quinto ano como professores polivalentes e os demais em disciplinas específicas (Quadro 2).

\begin{tabular}{|c|c|}
\hline Area de rormeriolo & Guantidade de professores \\
\hline Geografia & 2 \\
\hline Quimica & 1.3 \\
\hline Letras & 1 \\
\hline Magikterio nivel inedio & 2. \\
\hline Pedagogia & 3 \\
\hline Artes & 2. \\
\hline Biologia & 1 \\
\hline Iotal de protessores. & 12 \\
\hline
\end{tabular}

Quadro 2: Representação da amostra de professores quanto à área de formação.

${ }^{2} \mathrm{Na}$ época da pesquisa esses professores encontravam-se cursando a graduação.

Revbea, São Paulo, V. 11, № 1: 54-65, 2016. 
No tocante à compreensão dos professores sobre a concepção de meio ambiente (numa amostra de doze professores e de sete escolas) observou-se que $50 \%$ destes inseriram a dimensão da cultura, expressa pelas relações sociais, na concepção de meio ambiente. As falas transcritas dos professores e mencionadas a seguir demonstram essa visão.

Meio ambiente são todos os lugares que a gente vive. Todos os lugares que a gente vive, também fazem parte, até nossas relações sociais, tudo isso aí está implicado, também o ser humano. O próprio ser humano. Então o meio ambiente é tanto a Amazônia como o lugar que a gente está vivendo, nossa escola, o lugar por onde a gente anda no dia a dia, essa coisa toda (João - Artes- Escola A).

Constata-se que na compreensão do professor João, o meio ambiente é tanto o meio físico natural como o meio construído, incluindo-se também o homem e sua relação com esse meio.

Nas falas transcritas a seguir, o professor Eduardo e a professora Sara também demonstram compreender a existência da marca humana deixada na natureza pelas relações sociais, ao reconhecer o fato de que a sociedade, por suas necessidades, desenvolve-se em uma estreita relação com o seu entorno natural.

Na verdade, o meio ambiente, em linhas gerais, é tudo aquilo que nos rodeia. Até do ponto de vista conceitual. E quando a gente fala em tudo que nos rodeia, a gente reporta-se, imediatamente, aos elementos naturais? Os elementos constituintes da natureza, mas, como nesse meio natural existe a intervenção do homem, então essas intervenções promovidas pelo homem modificam esse meio ambiente que passa a interferir no modo de vida e na qualidade de vida das pessoas. O meio ambiente, na verdade, tende a comportar-se de acordo com a forma como ele é tratado (Eduardo Pedagogo - Polivalente - Escola B).

Meio ambiente para mim é o espaço onde a gente vive. $O$ espaço tanto ligado às questões de ambiente como também questões sociais, certo? Meio ambiente para mim é isso. É essa relação que a gente também tem de relacionamento, de questões de raça, de cor. Assim, esse ambiente para mim é isso? Onde você procura estabelecer harmonia entre eles, em qualquer sentido, tanto nas questões de fauna, de flora como também nas questões sociais (Sara Português - Escola D). 
O professor Juarez, ao falar o que pensa sobre o meio ambiente, considera que existe uma relação dinâmica entre sociedade e natureza intermediada pelo trabalho humano como parte constituinte do meio ambiente.

Bem, pra mim meio ambiente é o meio natural o qual nós vivemos? Está relacionado a tudo, aos recursos naturais, está relacionado à relação que o homem tem com esse meio ambiente, a relação de sobrevivência, está relacionado aos seres vivos, à diversidade, à biodiversidade, que é necessário para que haja equilíbrio. [...]. Meio ambiente é o meio natural, é a relação que o homem tem com esse meio. Essa relação seria principalmente pela questão do trabalho, que acredito que o homem torna-se ele homem no momento em que, através do meio ambiente, dessa natureza, busca os seus meios de sobrevivência, ou seja, ele vai desenvolver ali o trabalho com a finalidade de sobrevivência. Então, a partir desse momento, esse homem passa a ter relação como uma questão social. (Juarez - Pedagogo - Polivalente - Escola C).

Para o professor Juarez, a relação humana com a natureza dá-se pelo trabalho, a partir do momento em que o homem busca os meios de sobrevivência. Essa visão tem um sentido importante porque ao perceber a categoria "trabalho" como mediadora da relação humana com a natureza, possibilita enxergar outras singularidades. Como por exemplo, compreender em que condições o trabalho é mediador da degradação ambiental e social? Essa visão fornece meios para que o exame das "relações produtivas e mercantis revele as singularidades dos atores sociais, permitindo uma distinção mais acurada do causador (e da vítima) da crise ambiental do que simplesmente a humanidade" (LAYRARGUES, 2006, p. 80).

Nesse aspecto, problematizar a relação humana com a natureza é importante porque pode ajudar-nos a desvendar ideologias generalistas do tipo: "agressão humana com a natureza", "sociedade contra natureza", "culpa da humanidade". Expressões desse tipo, no entender de Layrargues (2006, p.80):

dilui os agentes sociais que, com suas respectivas responsabilidades diferenciadas, ficam não em segundo plano, mas literalmente ocultos. É a consideração da categoria "trabalho" que fornece a concretude necessária para que seja possível visualizar que os "humanos" não são seres vivos genéricos e abstratos para serem qualificados linearmente numa relação "humano-natureza" como é tão frequentemente posta, mais sim preenchidos de valores, interesses, intencionalidades e intervenção físicas no mundo bastante diferenciadas. 
Com efeito, perceber o diálogo existente entre a natureza e a sociedade possibilita compreender a permanente interação dessa relação. $\mathrm{Na}$ compreensão de Carvalho (2006, p. 82):

tal noção auxilia-nos a traduzir a indissociável interação entre o mundo natural e o social, da qual resultam as condições de vida humana na Terra e as marcas dessa presença na natureza, as quais criam permanentemente, no mundo, novos cursos de vida, fluxos de comunicação e paisagens tanto naturais quanto culturais.

Dessa maneira, abandona-se um conceito de meio ambiente, o qual está reduzido às suas condições físicas e biológicas de funcionamento e transcende-se para outra convicção, a de que "toda a formação social desenvolve-se numa estreita relação com e seu entorno natural" (LEFF, 2000, p. 95).

Entre as falas identificadas, seis (6) professores, o que corresponde aos outros $50 \%$ da amostra, abordaram uma compreensão naturalista sobre o meio ambiente, a qual corresponde à noção de espacialidade deslocada da interação humana na natureza, ou seja, refere-se ao lugar ${ }^{3}$ onde os indivíduos habitam e está relacionada ao espaço geográfico.

Destacamos, portanto, que na amostra analisada, $50 \%$ dos professores possuem uma representação de meio ambiente de cunho "naturalista", por conceberem o meio ambiente a partir de uma visão ecológica "reducionista", reduzida às dimensões físicas e biológicas da natureza. Ainda dentro dessa representação, identificamos duas visões: uma delas considera o meio ambiente a partir da noção de espacialidade, geralmente, relacionada ao lugar onde se habita. E outra, que articula a noção de espacialidade com os elementos físico-biológicos. Essa última visão está presente na metade da amostra que compreende o meio ambiente na sua dimensão naturalista.

As visões de meio ambiente expressas pelas professoras a seguir caracterizam bem essa perspectiva.

Então, meio ambiente é tudo que está relacionado com o meio aonde a gente vive, faz parte do meio aonde vivemos. A escola é nosso meio, onde moramos. Nosso bairro, nossa casa. Então, tudo isso faz parte do nosso meio ambiente (Maria Clara - Nível Médio - polivalente - Escola C).

\footnotetext{
${ }^{3}$ Essa definição de meio ambiente mais se aproxima do conceito de lugar na perspectiva da Geografia Humanística e cultural, perspectiva que a partir do enfoque fenomenológico valoriza o cotidiano, a experiência do indivíduo na relação com o meio. Tal abordagem considera o lugar como o espaço que se torna familiar ao indivíduo, o espaço vivido, experimentado cotidianamente.
} 
A minha ideia é que meio ambiente não é o seu local restrito e sim se referindo ao planeta Terra. No todo, eu vejo esse todo. O meio ambiente como um todo. Essa é minha visão. (Ângela Geografia - Escola A).

Meio ambiente para mim é todo espaço que é ocupado por seres vivos e não vivos. Um objeto que foi construído e está destruindo o meio ambiente. Tudo que está no universo, está relacionado com o planeta Terra eu considero o meio ambiente (Kaline - Pedagoga - Escola G).

O reducionismo mais expressivo na compreensão do meio ambiente foi observado na fala da professora Andréia, a qual é formada em biologia e ensina Ciências. Ao referir-se ao conceito o diluiu totalmente na idéia de biosfera.

O meio ambiente é o meio que se vive. É vamos dizer assim, o meio ambiente é o planeta. Onde existem os seres vivos. Biosfera. Eu diria que o meio ambiente está relacionado com a biosfera. Onde tem vida, é o meio ambiente (Andréia Ciências - Escola G).

Pode-se concluir, em relação à visão de meio ambiente predominante no universo da amostra pesquisada, que a compreensão do meio ambiente, enquanto inter-relações dinâmicas entre natureza e sociedade, interpretadas através das questões biofísicas, políticas, econômicas e culturais foram identificadas nas falas de seis (6) professores, o que constitui $50 \%$ da amostra. Por outro lado, essa visão está mais distante do repertório intelectual dos outros $50 \%$ dos professores entrevistados, que compreendem o meio ambiente a partir da visão reducionista, naturalista. Tal análise permite situá-la no interior da concepção ambiental que separa a natureza da cultura humana e quando esta se insere no fazer pedagógico da EA se circunscreve, ao mesmo tempo, no âmbito da Educação Ambiental conservadora ou comportamentalista.

Como características mais expressivas da EA conservadora ou comportamentalista, Gonzaga (2008), (2010) afirma que o enfoque desta vertente em relação à questão ambiental, apresenta uma compreensão naturalista e conservacionista da crise ambiental; aborda um entendimento reducionista, biologizante ou fragmentado sobre a questão ambiental; compreende a natureza como algo exterior que rodeia a vida humana.

Com bastante pertinência, Layrargues (2004a, p.12) destaca que "essa vertente enfatiza a dimensão ecológica em detrimento das demais contextualizações do problema ambiental, promovendo o entendimento da estrutura e funcionamento dos sistemas ecológicos, mas ignorando a sua interface com a dinâmica social". 
O entendimento desenvolvido pelos professores sobre o meio ambiente pode significar tanto o que representa o meio para eles como 0 universo cultural deixado pelas circunstâncias, opções de vida ao longo de suas trajetórias enquanto sujeitos no mundo, como bem salienta Carvalho (2006, p. 78): "a interpretação fala tanto do fenômeno interpretado quanto do mundo da vida e do universo cultural do sujeito que interpreta".

Quanto aos fenômenos interpretados e analisados, os quais estão representados pela visão de meio ambiente dos professores, podem reforçar diversos aspectos já discutidos ao longo da pesquisa desenvolvida. Entre eles, que a presença marcante da idéia naturalista predominante no conceito de meio ambiente significa que:

- A EA surgiu num ambiente marcado pela visão predominantemente naturalista;

- O campo da EA ainda não conseguiu superar o reducionismo reinante das práticas conservadoras em suas abordagens teórico-metodológicas;

- A EA é um campo de disputa conceitual e ideológico e ainda é marcante a visão que imperou nas primeiras discussões e conferências oficiais sobre o assunto;

- Ainda existe uma confusão entre o quê e como abordar na EA as temáticas sobre o assunto, levando a contundi-la, geralmente, com as aulas de ciências, biologia, ecologia e geografia;

- A EA é compreendida apenas como um instrumento que pode "conscientizar", moldar a mente dos indivíduos para estes agirem "corretamente" diante das questões ambientais.

Esses pontos são reforçados por Layrargues (2006, p. 87) ao analisar o itinerário já percorrido pela EA como processo que incluiu a dimensão ambiental na educação. Ele afirma que

nesse período, uma conjunção de fatores (como a concepção naturalista de meio ambiente, o predomínio de profissionais oriundos da biologia como educadores ambientais, o predomínio de órgãos governamentais ambientais como proponentes de políticas e programas de educação ambiental, a omissão científica na incorporação da educação ambiental, como um objeto de estudo da sociologia ambiental e da sociologia da educação) acarretou na ecologização da educação ambiental, moldando-a conforme uma educação conservacionista, confundida muitas vezes com o ensino de ecologia, quer dizer, o estudo da organização estrutural e funcionamento dos sistemas ecológicos, embora agora atravessado pela percepção da fragilidade de tais sistemas em função da ação antrópica.

Revbea, São Paulo, V. 11, № 1: 54-65, 2016.

revista brasileira 
O legado deixado por esse histórico da EA, que carrega heranças da dimensão técnico-gerencial dos recursos naturais $e$ a perspectiva comportamental, não podia ser outro, senão a diluição do meio ambiente aos aspectos meramente naturais, percebidos apenas por suas dimensões físicas e biológicas desconectadas dos processos sócio-históricos face ao meio ambiente, como bem salienta Loureiro (2002a, p. 71):

\begin{abstract}
a relação educação-política é amplamente discutida na produção teórica das Ciências Sociais e humanas, mas o reducionismo observado na produção específica em Educação Ambiental decorre da íntima associação que se fez entre a dimensão técnico-gerencial dos recursos naturais e a comportamental, a qual se expressa no processo de institucionalização da área de meio ambiente no país, pouco articulada com os setores voltados para a questão social, particularmente com as instâncias formais da educação.
\end{abstract}

Quando se referem ao meio ambiente, de modo mais abrangente, tanto os professores como os ambientalistas que atuam na educação dissociam os aspectos técnicos dos aspectos políticos e sociais. Essa separação ou omissão dos aspectos políticos e sociais dos fatores técnicos da questão ambiental pode ser parte de uma visão mercadológica que prioriza as gestões técnicas direcionadas para o mercado, em detrimento da questão política e social voltadas para a dimensão humana. Nesse sentido, a tecnificação ${ }^{4}$ da discussão ambiental na educação não deixa de fazer parte de um controle político e social da sociedade por parte de setores estratégicos que disputam projetos distintos de sociedade.

Quanto ao universo cultural do sujeito, que nesse caso diz respeito aos professores entrevistados, suas visões de meio ambiente podem sinalizar os possíveis itinerários destes profissionais.

$\mathrm{Na}$ amostra da pesquisa, observou-se que apenas um professor tinha especialização na área de Educação Ambiental, embora não se atribua uma relação direta em ter-se uma especialização em EA e uma visão de meio ambiente que não permite a dicotomia entre natureza e sociedade.

Outra questão que merece atenção é pensar sobre a própria estrutura curricular da maior parte dos cursos de licenciatura. Nesse caso, será que existe uma interlocução, pelo menos, a relação interdisciplinar das licenciaturas e a questão ambiental e social? E mesmo que exista atualmente essa relação, os professores integrantes da pesquisa formaram-se em outro

4 Usamos esse termo para designar processos que se desenvolvem na esfera social, tanto no campo de setores que lidam diretamente com a questão ambiental como da educação, que ao abordarem o meio ambiente direcionam para a tecnificação do assunto, privilegiando as questões científicas especificas, desconsiderando a relação política, ética e social do assunto.

Revbea, São Paulo, V. 11, № 1: 54-65, 2016. 
contexto, anterior à emergência do campo da $E A$, momento em que a educação e a sociedade não se debruçavam de modo mais amplo para a questão ambiental.

Mesmo ciente dos contextos sócio-históricos que conduzem a prática habitual dos professores ao reducionismo e a fragmentação da questão ambiental, não se deve camuflar ou inocular a ocorrência dessa perspectiva não transcender ou contribuir com aquilo que propõe enquanto objetivo do seu fazer pedagógico. Ou seja, educar para transformar. Pelo menos, à luz da EA que se fundamenta pela práxis.

\section{Considerações finais}

No que diz respeito às experiências pesquisadas, constatou-se o predomínio da Educação Ambiental conservadora no âmbito da prática educativa. Abordagem caracterizada pelo reducionismo na compreensão da questão ambiental, marcada principalmente pelo seu enfoque biologizante e ecologizante, o qual dilui ou desconecta as discussões econômicas, políticas, culturais e sociais da questão ambiental e ignora a sua interface com a dinâmica social, além de subjugar a ação humana no tecido social e negar, ao mesmo tempo, a existência do sujeito histórico.

Ainda assim, cabe reconhecer que, na atual conjuntura em que a Educação Ambiental se realiza e se afirma como campo de conhecimento específico da educação, o professor é, antes de tudo, sujeito de outros contextos sociais que transcendem as práticas escolares, cuja prática social envolve os papeis pai, aluno, filho, membro de organização social, incluindo sindicato, partido, religião, família, etc. e que estes afetam, sobremaneira, a vida e a atividade profissional do professor.

É importante reconhecer também que a qualidade social do trabalho do professor e, consequentemente, o retorno social que a escola devolve à sociedade, depende muito do tipo de vida que ele leva, de suas convicções morais, éticas, políticas, de sua situação salarial, de sua satisfação em estar no campo da educação, enquanto profissional do ramo e mais ainda do compromisso político e social do poder público em face aos fins e interesses da educação. Tudo isso são questões que afetam em muito as feições individuais dos professores e da educação coletivamente. Mesmo assim, diante dos limites e condições adversas impostas aos professores é possível perceber que muitos são portadores de grandes valores, criatividade e potencial enérgico com capacidade imensa de elevar a Educação Ambiental do campo da "ingenuidade", despolitização e passividade para o campo de uma práxis pedagógica plena, portanto, mais apta a imprimir movimentos de transformação social para se atingir a mudança ambiental desejada.

Nesse sentido, a constituição de uma Educação Ambiental crítica, transformadora, emancipatória, reveladora dos conflitos socioambientais, não se faz presa à armadilha da visão produtivista e mercadológica de educação que subordina as funções sociais da educação e da escola conforme têm sido 
aprisionadas historicamente de forma planejada e controlada, apenas para atender às demandas do capital e de seus interesses imanentes.

A Educação Ambiental proposta nesse estudo à sociedade é oposta à Educação Ambiental conservadora, consolidada como uma prática pedagógica que escamoteia os conflitos sociais, que esconde as mazelas da periferia e cria outros focos de atenção impedindo se enxergar as contradições que se materializam no modo de produção capitalista.

Propõe-se, ainda, ampliar o alcance da Educação Ambiental de modo que ela não se limite aos processos formais de ensino, mas também envolva um amplo conjunto de práticas sociais e educativas que se desenvolvam fora da escola por meio de crianças, jovens, adultos, líderes comunitários locais, caracterizando-a também como uma Educação Ambiental de caráter popular.

Nesse cenário, a Educação Ambiental não deixa de ser um mecanismo ideológico de reprodução dos valores da sociedade capitalista. Mas, é também, dialeticamente, uma via por onde caminha a disputa pela conservação da ordem social vigente ou transformação das condições sociais.

Portanto, o momento exige esforços individuais e coletivos para mudar tanto a sociedade que impõe formas de relação humano-naturezasociedade causadoras da crise social e ambiental como a Educação Ambiental que sugere a conservação da ordem social vigente.

\section{Referências}

BRUGGER, P. Educação ou adestramento ambiental? Florianópolis: Letras Contemporâneas, 1999.

CARVALHO, I.C.M. Um balanço da produção científica em educação ambiental de 2001 a 2009. Revista Brasileira de Educação v. 16 n. 46 jan.|abr. 2011.

CARVALHO, I.C.M. Educação ambiental: a formação do sujeito ecológico. 2. ed. São Paulo: Cortez, 2006. (Coleção Docência em formação).

GONZAGA, M.J.B. Educação Ambiental: um estudo de experiências em escolas municipais de Natal. 2008. 160 f. Dissertação (Mestrado em Ciências Sociais) - Programa de Pós-Graduação em Ciências Sociais, Centro de Ciências Humanas, Letras e Artes, Universidade Federal do Rio Grande do Norte, Natal, 2008.

GONZAGA, M.J.B. Educação ambiental: uma análise de experiências em escolas públicas de natal (RN) In: CABRAL NETO, A. (Org). Educação ambiental: caminhos traçados, debates políticos e práticas escolares. Brasília: Líber Livro Editora, 2010. 240 p.

GUIMARÃES, M. Educação ambiental: no consenso um embate? Campinas: Papirus, 2002. 
LAYRARGUES, P.P. Muito além da natureza: educação ambiental e reprodução social. In: LOUREIRO, Carlos Frederico Bernardo. et al. Pensamento complexo, dialética e educação ambiental. São Paulo: Cortez, 2006.

LAYRARGUES, P.P. O cinismo da reciclagem: o significado ideológico da lata de alumínio e suas implicações para a educação ambiental. In: LOUREIRO, Carlos Frederico Bernardo. et al. Educação ambiental: repensando o espaço da cidadania. 2. ed. São Paulo: Cortez, 2002.

LAYRARGUES, P. P. Para que a educação ambiental encontre a educação. In: LOUREIRO, C. F. B. Trajetória e fundamentos da educação ambiental. São Paulo: Cortez, 2004a.

LEFF, H. Ecologia, capital e cultura: racionalidade ambiental, democracia participativa e desenvolvimento sustentável. Blumenau: Edifurb, 2000.

LIMA, G.F.C. Crise Ambiental, educação e cidadania: os desafios da sustentabilidade emancipatória. In: LOUREIRO, C. F. B.; LAYRARGUES, P. P.; CASTRO, R. S. (Org.). Educação ambiental: repensando o espaço da cidadania. 2. ed. São Paulo: Cortez, 2002.

LOUREIRO, C.F.B. Trajetória e fundamentos da educação ambiental. São Paulo: Cortez, 2004.

LOUREIRO, C.F.B. Pensamento complexo, dialética e educação ambiental. São Paulo: Cortez, 2006.

LOUREIRO, C.F.B. et al. Educação ambiental: repensando o espaço da cidadania. 2. ed. São Paulo: Cortez, 2002a.

RUSCHEINSKY, A. A pesquisa em história oral e a produção de conhecimento em educação ambiental. In: SATO M.; CARVALHO, I.C.M. Educação ambiental: pesquisa e desafios. Porto Alegre: Artmed, 2005. 